\title{
STUDY OF NEONATAL MORBIDITY PROFILE IN NICU AT A TERTIARY CARE TEACHING HOSPITAL (KGH, VISAKHAPATNAM)
}

\author{
D. Ramaganeshan 1 , P. Ramu², J. Ravi Teja 3 , K. Vidya Sagar Reddy4
}

${ }^{1}$ Associate Professor, Department of Paediatrics, Andhra Medical College, King George Hospital, Visakhapatnam. ${ }_{2}^{2}$ Assistant Professor, Department of Paediatrics, Andhra Medical College, King George Hospital, Visakhapatnam. 3Junior Resident, Department of Paediatrics, Andhra Medical College, King George Hospital, Visakhapatnam. 4Junior Resident, Department of Paediatrics, Andhra Medical College, King George Hospital, Visakhapatnam.

\section{ABSTRACT}

\section{CONTEXT (BACKGROUND)}

India accounts for highest number of annual births ( 25.6 million) and neonatal deaths ( 0.76 million or $30 \%$ global burden). There is paucity of published data on new born health care from our country. We studied the morbidity profile of newborns admitted in our NICU.

\section{MATERIAL AND METHODS}

This retrospective study on the morbidity profile of newborns was conducted at Neonatal Intensive Care Unit (NICU) of a tertiary care teaching hospital - King George Hospital, Visakhapatnam between May 2014 and April 2016 (2 years). All neonates admitted in our NICU during the above period were reviewed regarding place of birth, gestational age, birth weight, primary diagnosis at admission and other associated comorbidities.

\section{AIM}

To study the morbidity profile in our NICU, a tertiary care teaching hospital during 2 years study period.

\section{RESULTS}

In the present study, the data of 5755 neonates who were admitted in our NICU were analysed. Out of them 2994 (52.02\%) were inborn and 2761 were out-born (47.98\%). In our study population slight male preponderance, more number of pre-term babies $(3513,61.05 \%)$ that too gestational age between $34-37$ weeks $(2299,39.95 \%)$ occupied the major share. In our study, the major cause of morbidity was RDS 1127 (19.58\%) followed by HIE/birth asphyxia 1053 (18.30\%), neonatal jaundice 920 (15.99\%), sepsis $673(11.70 \%)$ and miscellaneous causes $784(13.62 \%)$ out of 5755. In our study, about 81 babies (1.41\%) had major congenital malformations.

\section{CONCLUSION}

Our study identified pre-term babies (57.57\%), respiratory distress syndrome (19.58\%), HIE (18.30\%), neonatal jaundice $(15.99 \%)$ and sepsis $(11.70 \%)$ as major causes of neonatal morbidity out of 5755 NICU admissions. Most of these morbidities are preventable up to some extent if detected and intervened in time, so as to reduce the morbidity and mortality.

\section{KEYWORDS}

Morbidity profile, NICU, Neonatal Mortality Rate (NMR), Sepsis, Hyaline Membrane Disease (HMD), Respiratory Distress Syndrome (RDS), Meconium Aspiration Syndrome (MAS), Hypoxic Ischaemic Encephalopathy (HIE), Intrauterine Growth Retardation (IUGR).

HOW TO CITE THIS ARTICLE: Ramaganeshan D, Ramu P, Teja JR, et al. Study of neonatal morbidity profile in NICU at a tertiary care teaching hospital (KGH, Visakhapatnam). J. Evolution Med. Dent. Sci. 2016;5(67):4809-4814, DOI: 10.14260/jemds/2016/1096

\section{INTRODUCTION}

Globally 130 million babies are born every year and of these 4 million die during the neonatal period, i.e. first 4 weeks of life. A similar number of babies are still born accounting for 8 million perinatal deaths per year, i.e. 15 lives are lost every minute.

Financial or Other, Competing Interest: None.

Submission 10-06-2016, Peer Review 27-07-2016,

Acceptance 02-08-2016, Published 22-08-2016.

Corresponding Author:

Dr. P. Ramu,

Raja Sagi Residency, FF-3,

Door No: 14-1-122/13,

Nowroji Road, Maharanipeta,

Visakhapatnam-530002,

Andhra Pradesh.

E-mail: drpramu73@gmail.com

DOI: $10.14260 /$ jemds/2016/1096
India accounts for highest number of annual births (25.6 million) and neonatal deaths (0.76 million or $30 \%$ global burden). Hence, the importance of new born care at all levels is all concern. Most neonatal deaths occur in the first week of life (75\%) and almost $25 \%$ during the first 24 hours of life. The risk of mortality during the neonatal period is 30 fold higher than post-neonatal period. Asphyxia, low birth weight, hypothermia and infections have been identified as the major causes of neonatal morbidity and mortality in India. We studied the neonatal morbidity profile in our NICU. ${ }^{1}$

\section{MATERIAL AND METHODS}

This retrospective study on the neonatal morbidity profile was conducted at NICU of tertiary care teaching hospital, King George Hospital, Visakhapatnam for a period of two years (May 2014 to April 2016). Ours is tertiary care referral centre for nearby 3-4 districts. 
A total of 5755 neonates both inborn and out-born admitted during the above said two years were enrolled on a well-structured protocol and reviewed the data regarding place of delivery, birth weight/weight at admission, sex of the baby, gestational age, primary diagnosis at admission and relevant investigations. Diagnosis of the neonatal clinical condition (Morbidity) was made as per guidelines given by NNF (National Neonatology Forum). ${ }^{2}$

\section{Statistics}

Morbidity proportions for inborn and out-born patients were analysed using Chi-square $\left(\mathrm{X}^{2}\right)$ test statistics and applied to find out $p$ value in variables. $P$ value of $<0.05$ is considered to be statistically significant for any given measure (Table 8).

\section{RESULTS}

In the present study, the data of 5755 neonates who were admitted in our NICU were analysed. Out of them, 2994 (52.02\%) are inborn and 2761 are out-born (47.98\%) (Table 1). In our study population, slight male preponderance (Table 2 ), more number of pre-term babies (Table 3) of gestational age between 34 and 37 weeks have occupied the major share 2299 (39.95\%) (Table 4). Among the term babies we had 190 (8.59\% of total term babies, 2213 and 3.30 of total study population) Intrauterine Growth Retarded (IUGR) babies (Table 5). Since major share in our study population is contributed by pre-term babies, the same was reflected in birth weight or weight at admission in which babies weighing less than 1500 gm have occupied the major proportion (Table 6). In our study, the major cause of morbidity was RDS 1127 (19.58\%) followed by HIE/Birth asphyxia 1053 (18.30\%), neonatal jaundice 920 (15.99\%) and sepsis 673 (11.70\%). Miscellaneous causes such as Amniotic fluid aspiration, Birth asphyxia, for pre-term care, Infant of diabetic mother, dysmorphic babies, minor congenital anomalies and others, 784 out of 5755 (13.62\%) (Table 7). In our study about 81 babies $(1.41 \%)$ had major congenital malformations of which neural tube defects, congenital heart diseases, cleft lip with or without cleft palate, congenital diaphragmatic hernia, tracheoesophageal fistula and skeletal anomalies are frequent observations (Figure 8 to Figure 17).

\begin{tabular}{|c|c|c|}
\hline Total Number & $\mathbf{( 5 7 5 5 )}$ & \% \\
\hline Inborn & 2994 & 52.02 \\
\hline Out-born & 2761 & 47.98 \\
\hline \multicolumn{2}{|c|}{ Table 1: Distribution of Inborn and Out-born Babies } \\
in the Present Study \\
\hline
\end{tabular}

\begin{tabular}{|c|c|c|}
\hline Total No. of Cases & 5755 & $100 \%$ \\
\hline Males & 3339 & $58.02 \%$ \\
\hline Females & 2416 & $41.98 \%$ \\
\hline
\end{tabular}

\begin{tabular}{|c|c|c|c|c|}
\hline $\begin{array}{c}\text { Gestational } \\
\text { Age }\end{array}$ & Inborn & $\begin{array}{c}\text { Out- } \\
\text { born }\end{array}$ & Total & $\begin{array}{c}\text { \% } \\
\text { (n=5755) }\end{array}$ \\
\hline Term & 1224 & 989 & 2213 & 38.45 \\
\hline Pre-term & 1749 & 1764 & 3513 & 61.05 \\
\hline Post-term & 21 & 8 & 29 & 0.50 \\
\hline Table 3: Distribution of Term, Pre-term \& Post-term \\
Babies in the Present Study \\
\hline
\end{tabular}

\begin{tabular}{|c|c|c|c|c|}
\hline $\begin{array}{c}\text { Gestational } \\
\text { Age }\end{array}$ & Inborn & Out-born & Total & $\%$ \\
\hline$>37$ weeks & 1245 & 997 & 2242 & 38.95 \\
\hline $34-37$ weeks & 1151 & 1148 & 2299 & 39.95 \\
\hline$<34$ weeks & 598 & 616 & 1214 & 21.10 \\
\hline Table 4: Expected Gestational Age at Admission \\
(Present Study n = 5755) \\
\hline
\end{tabular}

\begin{tabular}{|c|c|c|}
\hline $\mathbf{n}=\mathbf{2 2 1 3}$ & Number of Babies & $\mathbf{\%}$ \\
\hline Term with AGA & 2023 & 91.41 \\
\hline Term with SGA (IUGR) & 190 & 8.59 \\
\hline Table 5: Distribution of Term with AGA and IUGR Babies \\
in Our Study ( $\mathrm{n}=\mathbf{2 2 1 3}$ ) \\
\hline
\end{tabular}

\begin{tabular}{|c|c|c|c|c|}
\hline Weight in Grams & Inborn & Out-born & Total & $\%$ \\
\hline$>2500 \mathrm{gm}$ & 1404 & 1337 & 2741 & 47.63 \\
\hline $1500-2499 \mathrm{gm}$ & 1052 & 868 & 1920 & 33.36 \\
\hline $1000-1499 \mathrm{gm}$ & 431 & 438 & 869 & 15.10 \\
\hline$<1000 \mathrm{gm}$ & 107 & 118 & 225 & 3.91 \\
\hline Table 6: Birth Weight or Weight at Admission \\
(Present Study n = 5755) \\
\hline
\end{tabular}

\begin{tabular}{|c|c|c|c|c|}
\hline \multirow{2}{*}{$\begin{array}{c}\text { Morbidity } \\
\text { Respiratory } \\
\text { distress } \\
\text { syndrome }\end{array}$} & \multirow{2}{*}{$\begin{array}{c}\begin{array}{c}\text { Inborn } \\
=2994\end{array} \\
528\end{array}$} & \multirow{2}{*}{$\begin{array}{c}\begin{array}{c}\text { Out-born } \\
=2761\end{array} \\
599\end{array}$} & \multicolumn{2}{|c|}{$\begin{array}{c}\text { Total } \\
\text { Number \% }\end{array}$} \\
\hline & & & 1127 & 19.58 \\
\hline $\begin{array}{l}\text { Meconium } \\
\text { aspiration } \\
\text { syndrome }\end{array}$ & 357 & 210 & 567 & 9.85 \\
\hline $\begin{array}{l}\text { Other causes of } \\
\text { respiratory } \\
\text { distress }\end{array}$ & 217 & 163 & 380 & 6.60 \\
\hline $\begin{array}{l}\text { HIE/Moderate- } \\
\text { to-severe birth } \\
\text { asphyxia }\end{array}$ & 488 & 565 & 1053 & 18.30 \\
\hline $\begin{array}{c}\text { Sepsis/Pneumon } \\
\text { ia/Meningitis }\end{array}$ & 329 & 344 & 673 & 11.70 \\
\hline $\begin{array}{l}\text { Major congenital } \\
\text { malformations }\end{array}$ & 26 & 55 & 81 & 1.41 \\
\hline $\begin{array}{c}\text { Jaundice } \\
\text { requiring } \\
\text { phototherapy }\end{array}$ & 582 & 338 & 920 & 15.99 \\
\hline Hypothermia & 38 & 41 & 79 & 1.37 \\
\hline Hypoglycaemia & 52 & 39 & 91 & 1.58 \\
\hline Miscellaneous & 377 & 407 & 784 & 13.62 \\
\hline
\end{tabular}

Table 7: Morbidity Profile of Neonates at the Time of Admission (Present Study $n=5755$ )

\begin{tabular}{|c|c|c|c|c|}
\hline Morbidity & $\begin{array}{c}\text { Inborn } \\
\mathbf{2} \mathbf{2 9 9 4}\end{array}$ & $\begin{array}{c}\text { Out- } \\
\text { born } \\
= \\
\mathbf{2 7 6 1}\end{array}$ & $\mathbf{X}^{\mathbf{2}}$ & $\mathbf{p}$ \\
\hline $\begin{array}{c}\text { Respiratory distress } \\
\text { syndrome }\end{array}$ & 528 & 599 & 15.03 & 0.0001 \\
\hline $\begin{array}{c}\text { Meconium } \\
\text { aspiration syndrome }\end{array}$ & 357 & 210 & 30.15 & 0.0001 \\
\hline $\begin{array}{c}\text { Other causes of } \\
\text { respiratory distress }\end{array}$ & 217 & 163 & 4.20 & 0.04 \\
\hline $\begin{array}{c}\text { HIE/Moderate-to- } \\
\text { severe birth } \\
\text { asphyxia }\end{array}$ & 488 & 565 & 16.2 & 0.0001 \\
\hline
\end{tabular}




\begin{tabular}{|c|c|c|c|c|}
\hline $\begin{array}{c}\text { Sepsis/Pneumonia } \\
\text { /Meningitis }\end{array}$ & 329 & 344 & 3.008 & 0.08 \\
\hline $\begin{array}{c}\text { Major congenital } \\
\text { malformations }\end{array}$ & 26 & 55 & 13.06 & 0.0003 \\
\hline $\begin{array}{c}\text { Jaundice requiring } \\
\text { phototherapy }\end{array}$ & 582 & 338 & 29.7 & 0.0001 \\
\hline Hypothermia & 38 & 41 & 0.40 & 0.40 \\
\hline Hypoglycaemia & 52 & 39 & 0.90 & 0.30 \\
\hline Miscellaneous & 377 & 407 & 0.03 & 0.80 \\
\hline Table 8: Statistical Analysis of Morbidity Profile in the \\
Present Study (n=5755) \\
\hline
\end{tabular}

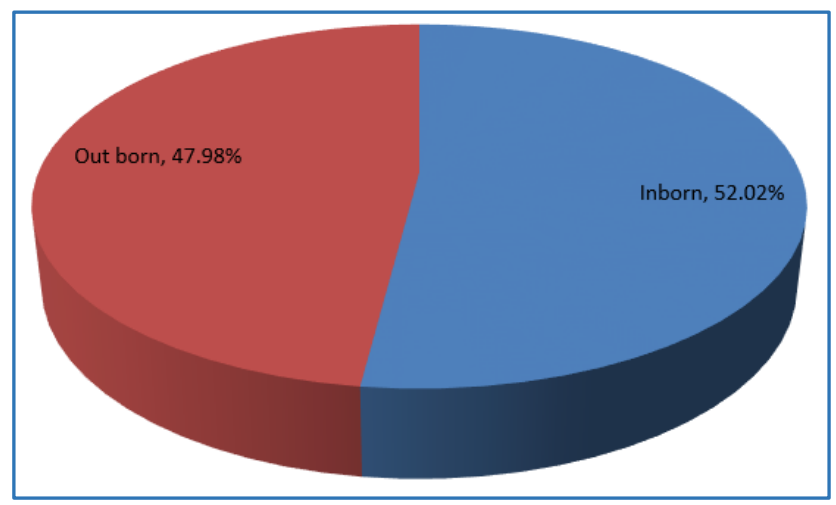

Fig. 1: Pie Diagram showing Percentages of in Inborn and Out-born Babies in Our Study (In \%)

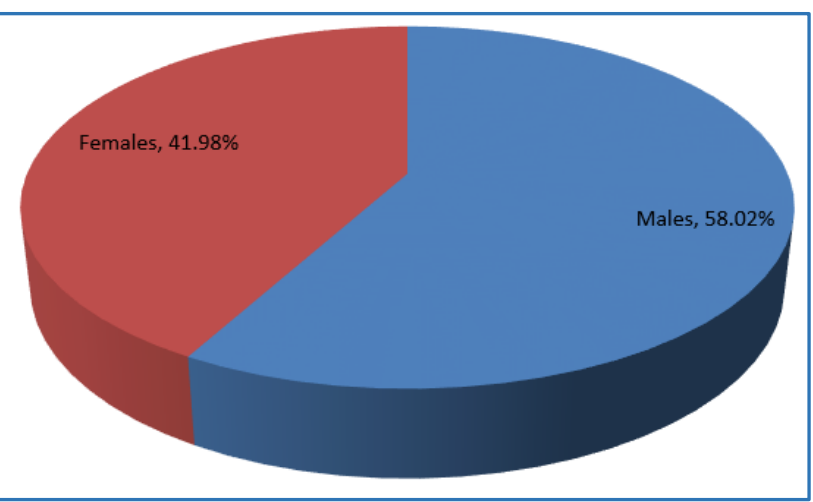

Fig. 2: Pie Diagram showing Sex Distribution in Our Study (In \%)

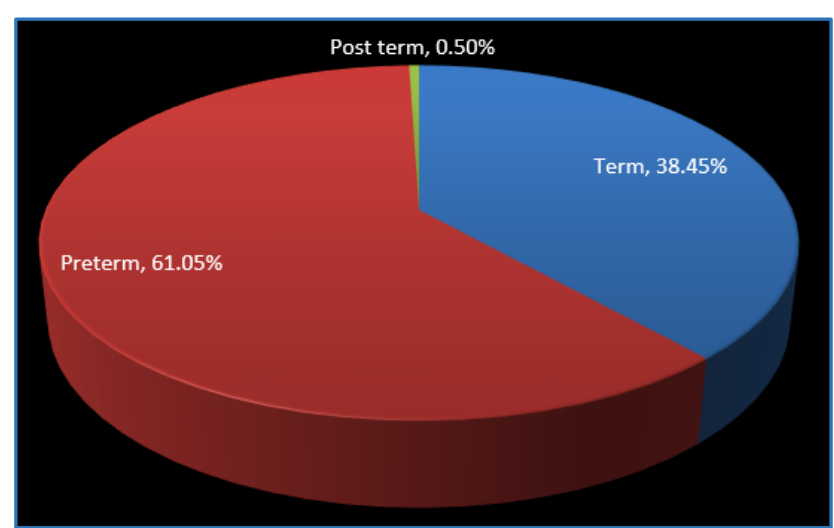

Fig. 3: Pie Diagram showing Distribution of Term, Preterm \& Post-Term in Our Study Population (In \%)

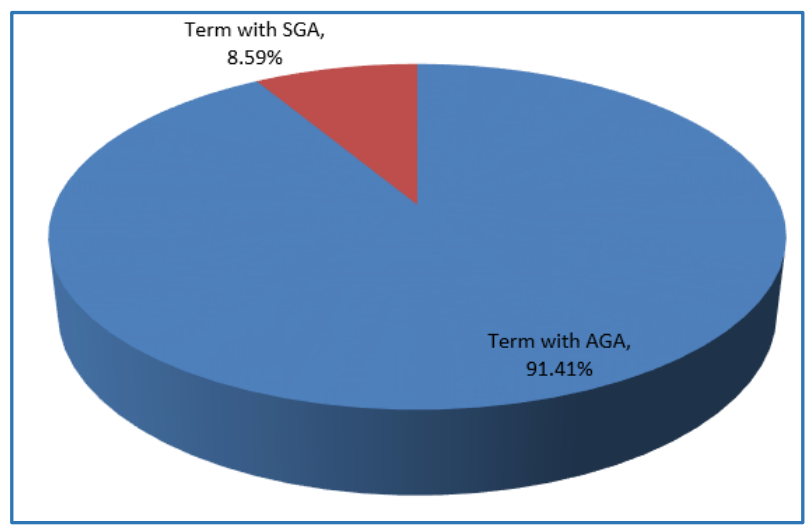

Fig. 4: Pie Diagram showing Distribution of Term with AGA and IUGR Babies in Our Study ( $n=2213$, In \%)

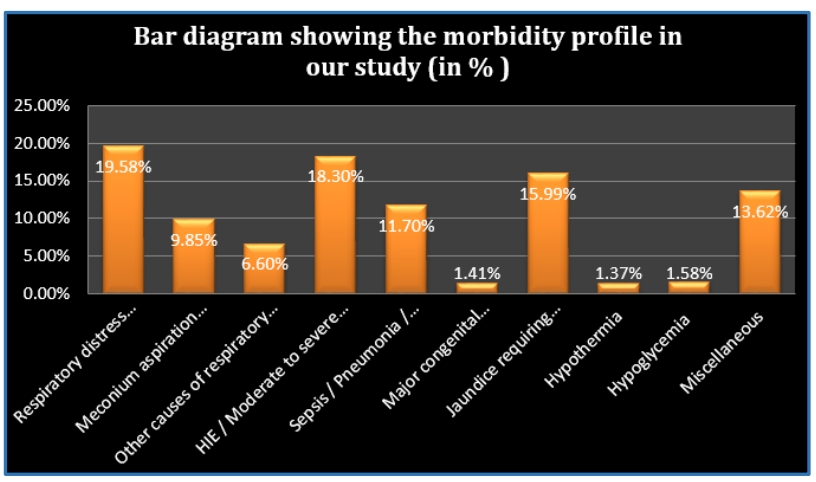

Fig. 5

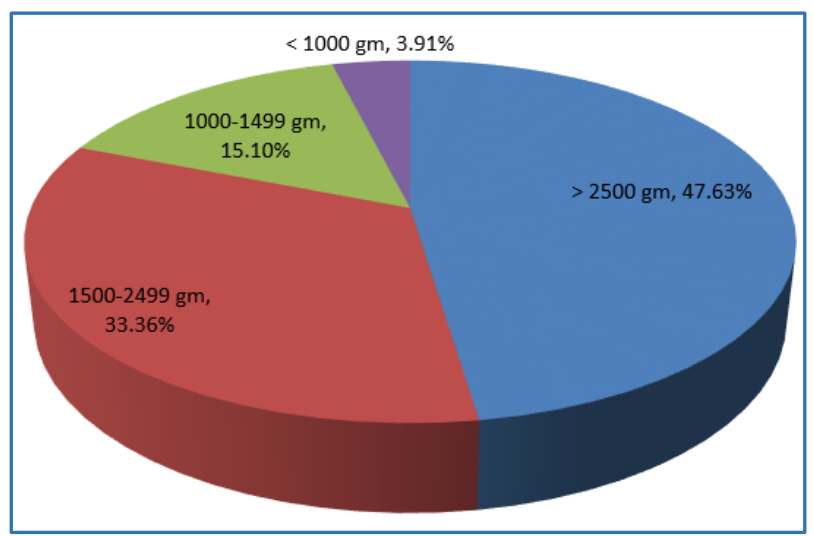

Fig. 6: Pie Diagram showing Weight Wise Distribution of Study Population (In \%)

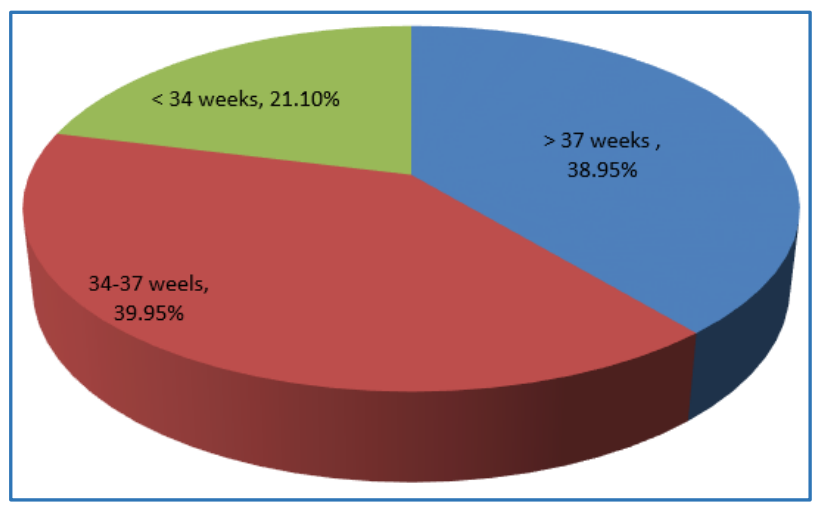

Fig. 7: Pie Diagram showing Gestational Age Wise Distribution of Preset Study Population (In \%) 


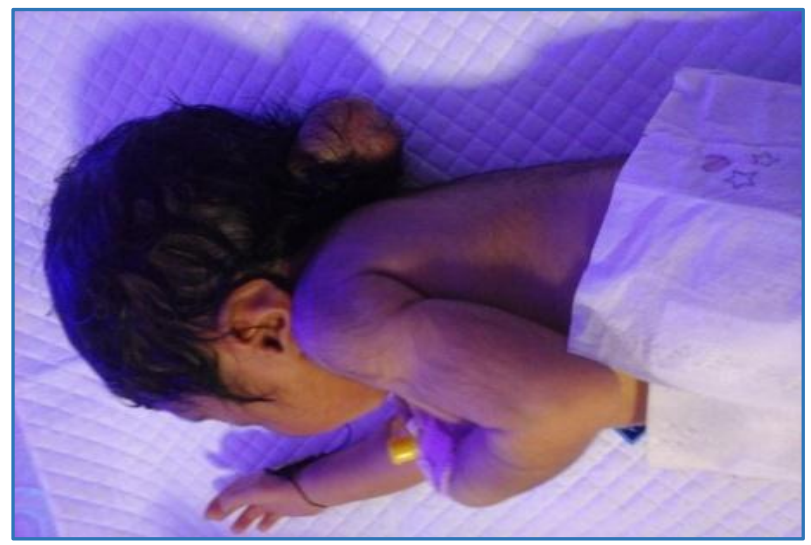

Fig. 8: Small Occipital Meningoencephalocele

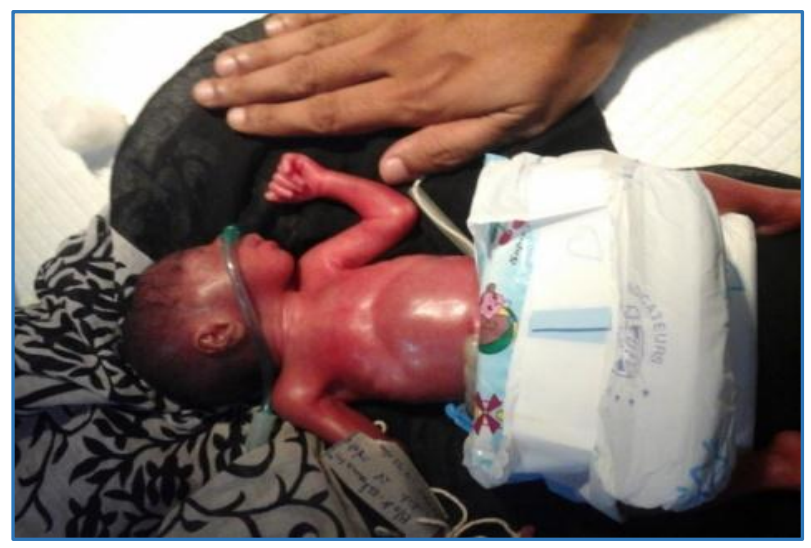

Fig. 9: Extremely Pre-term Baby 24-26 Weeks Gestational Age (Birth Weight : 540 gm)

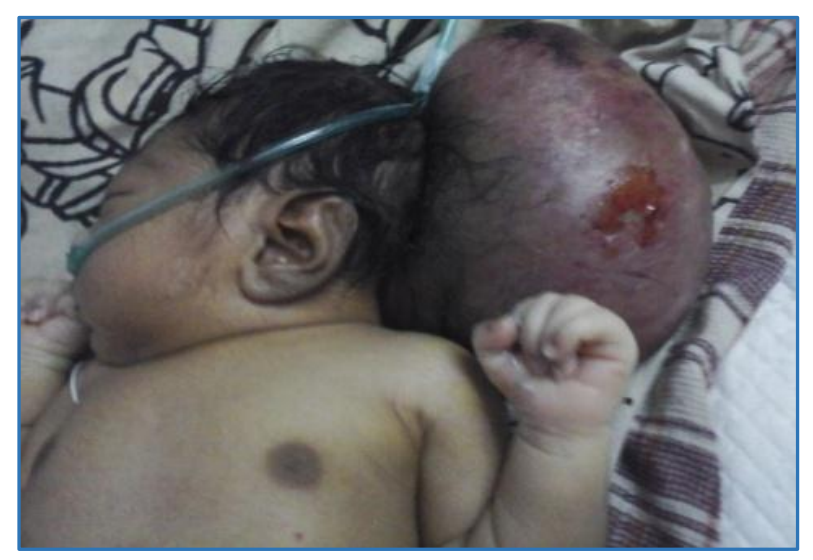

Fig. 10: Large Occipital Meningoencephalocele

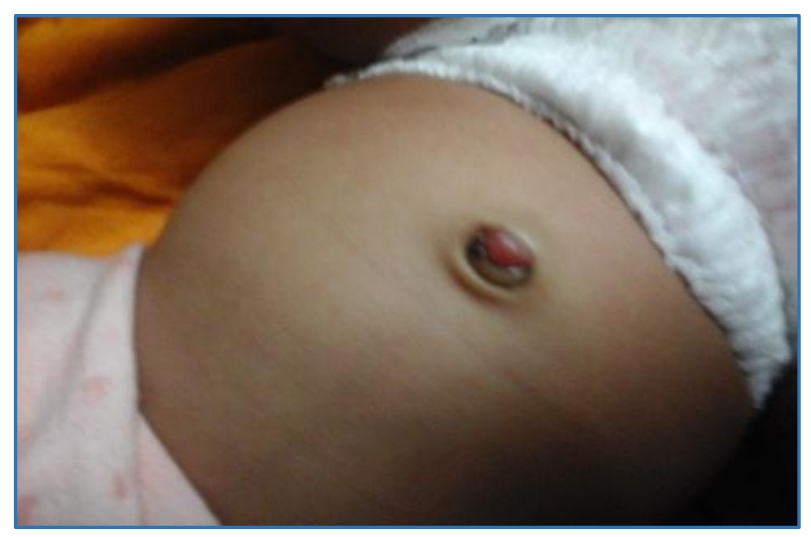

Fig. 11: Umbilical Granuloma

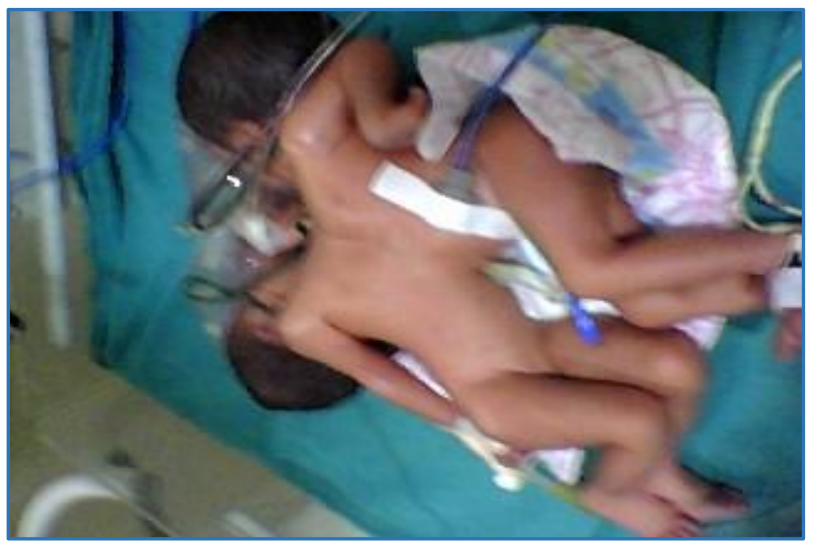

Fig. 12: Conjoined Twins (Thoracopagus) with Single Heart

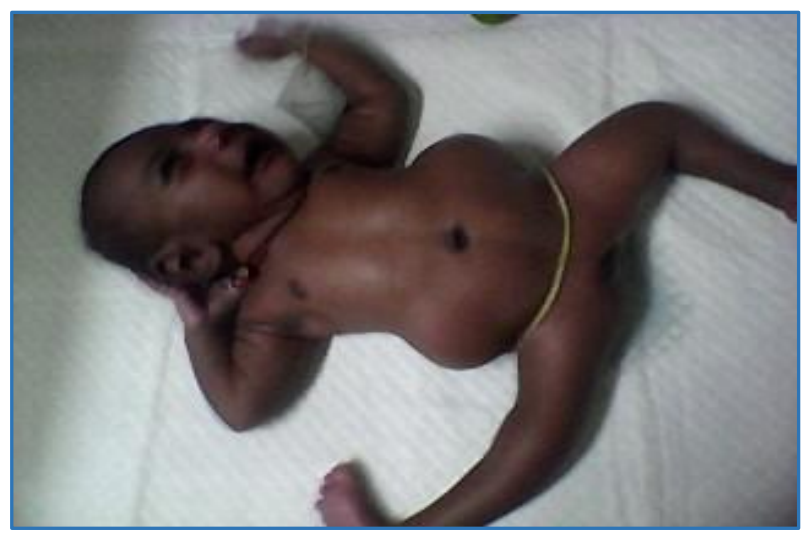

Fig. 13: Microcephaly with Skeletal Deformity

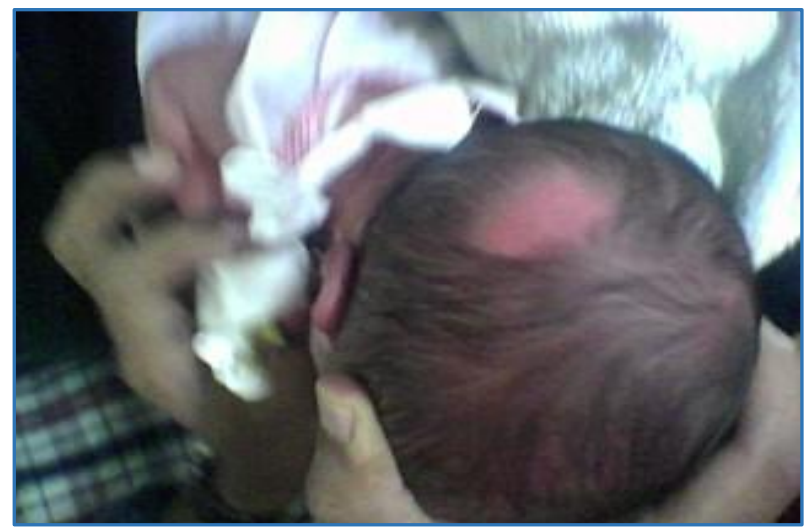

Fig. 14: Aplasia Cutis Congenita

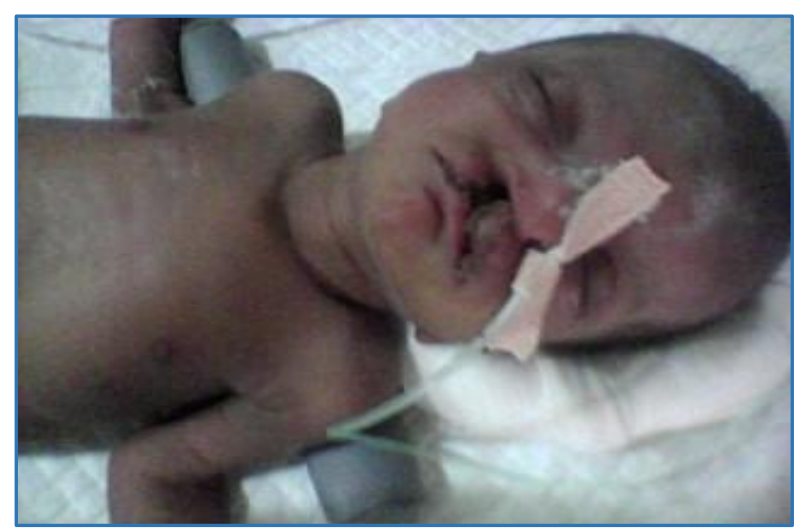

Fig. 15: Cleft Lip with Cleft Palate 


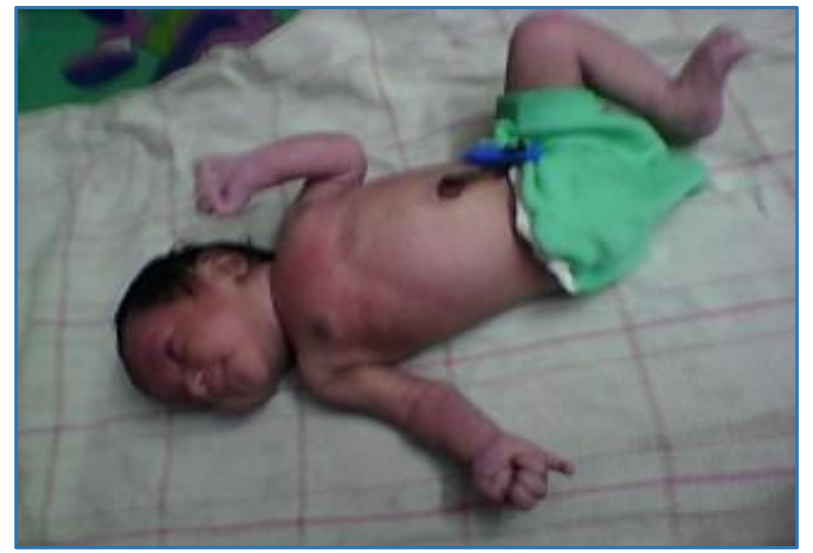

Fig. 16: Newborn with Complete Absence of Right Lower Limb

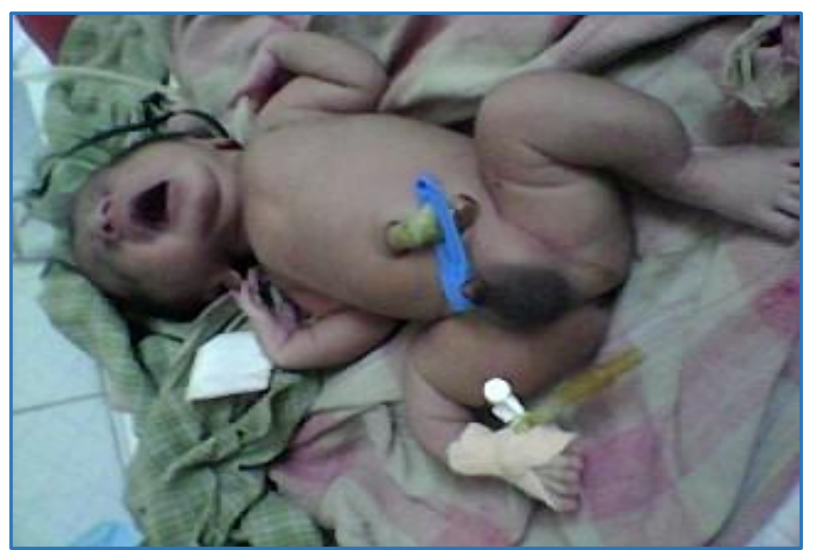

Fig. 17: Osteogenesis Imperfecta

\section{DISCUSSION}

According to analysis of 3.6 million neonatal deaths from 192 countries in 2010 , the main direct causes of neonatal deaths include pre-term births (29\%), severe infections (29\%), birth asphyxia (23\%), congenital malformations (8\%). In the United States, approximately 50\% of infant deaths in 2011 were a consequence of 4 conditions (Classified according to the International Classification of Diseases, $10^{\text {th }}$ revision): congenital malformations (20.1\%), disorders relating to prematurity and unspecified LBW (16.9\%), sudden infant death syndrome $(8.2 \%)$ and newborns affected by maternal complications of pregnancy (6.3\%). ${ }^{3}$ Whereas in developing countries, LBW/prematurity, birth asphyxia and infections are the major causes of infant deaths. Almost 99\% of neonatal deaths occur in developing countries. The current NMR (Neonatal Mortality Rate) in India is around 29 per 1000 live births and it accounts for $69 \%$ of infant deaths (IMR-42) and $56 \%$ of Under 5 Child Mortality (U5MR-52). NMR in rural areas is over one and a half times that of urban areas. In the United States each year approximately 6 million pregnancies, 4 million live births, 19,000 neonatal deaths and 28,000 infant deaths occur. Newborn care is assuming more and more importance in both developed and developing countries. In India, the birth of National Neonatology Forum (NNF, 1980) marked a great era in training of doctors and health workers in newborn care. World Health Organization (WHO), United Nations International Children's Fund (UNCEF) and Government of India (GOI) realizing the importance of newborn care have allocated huge grants for training health workers and doctors at Level I, II and III newborn care settings.
Level I care is provided at home, sub-centres and primary health centres by the mother, Trained Birth Attendant (TBA) and Public Health Nurses (PHN) under the supervision of primary health centre doctors. Almost $85 \%$ of newborns will require only this care. Level II care is provided at taluk and district head quarter hospitals by trained nurses under a paediatrician in a neonatal nursery. About $10-15 \%$ of babies between 33-35 weeks gestation (1.5-1.8 kg weight) will require this care. Level III care is provided in teaching institutions and apex hospitals by specially trained nurses and neonatologists. There should be facilities for long-term assisted ventilation, mobile X-ray, ultrasound machines, invasive and non-invasive monitors and total parenteral nutrition. Paediatric surgery facilities should also be available. Approximately, 3-5\% of babies with gestational age of $<33$ weeks and weighing $<1.5 \mathrm{~kg}$ will require this care. ${ }^{4}$

Low birth weight (LBW - Birth weight $<2500$ gm) babies have higher morbidity and mortality. LBW results from either pre-term birth (Before 37 completed weeks of gestation) or due to Intrauterine Growth Retardation (IUGR) or both. They are at high risk for perinatal asphyxia, hypothermia, hypoglycaemia, infections, polycythaemia, anaemia, etc. Approximately, $30 \%$ of babies delivered in India are Low Birth Weight (LBW) (birth weight $<2.5 \mathrm{~kg}$ ) as against $10 \%$ in the west. In our present study, more number of pre-term babies $(3513,61.05 \%)$ were admitted. The incidence of pre-term births in our country is $8-10 \%$ similar to the West. Thus $2 / 3 \mathrm{rd}$ of all LBW babies in India are term babies. Almost $75 \%$ of neonatal deaths occur among the LBW babies. LBW (as a result of pre-term delivery and/or IUGR) is a major determinant of both neonatal and infant mortality rates and together with congenital anomalies (Cardiac, central nervous system, respiratory), contributes significantly to childhood morbidity. Low Birth Weight (LBW) babies, babies of weight $<2500$ gm (Up to and including $2499 \mathrm{gm}$ ) irrespective of period of gestation are designated as LBW babies. These include preterm (1/3rd) and small for date term (2/3rd) babies. In India, for purposes of specialized care babies with a birth weight of $<1800$ gm are considered high risk and are admitted to the Special Care Neonatal Unit (SCNU). The current incidence of LBW babies in India is around 28\% (Lowest incidence of 7.6\% in Mizoram) accounting for 8 million LBW babies (40\% of global deaths every year. However, over $80 \%$ of LBW babies are good sized and weigh between 1500 gm and 1999 gm). Preterm babies are at higher risk of getting hypothermia, hypoglycaemia, anaemia, Intraventricular Haemorrhage (IVH), Respiratory Distress Syndrome (RDS), Hyaline Membrane Disease (HMD), Retinopathy of Prematurity (ROP), hearing loss, infections, etc. Respiratory distress in the neonate is a common problem and it can be a serious neonatal emergency. Respiratory and non-respiratory causes (Cardiac, metabolic, neurological) can lead to respiratory distress in neonates. In pre-term babies, HMD (RDS) is a common morbidity, especially $<34$ weeks gestational babies. Overall incidence is $10-15 \%$, but it can be as high as $80 \%$ in neonates $<28$ weeks gestation. Whereas in term and post-term Meconium Aspiration Syndrome (MAS) or amniotic fluid aspiration can cause respiratory distress.5,6 Pneumonia or sepsis can be a cause for respiratory distress in both term and pre-term babies. Infection by bacteria constitute a common morbidity and accounts for nearly $1 / 3$ rd of neonatal deaths. ${ }^{7}$ 
The incidence of birth asphyxia/perinatal asphyxia is 1$1.5 \%$ of all live births in developed countries and may be three times higher in developing countries. It constitutes a major cause of neonatal deaths and is the most common cause of neonatal convulsions. Jaundice due to physiological immaturity of newborn babies is seen in nearly $60 \%$ of term newborns and $80 \%$ of pre-term newborns. Neonatal jaundice is the commonest abnormal physical finding during the first week of life. High bilirubin levels may be toxic to the developing central nervous system and may cause neurological impairment like kernicterus or even fatal sometimes. In our study, the three major morbidities include respiratory distress syndrome (19.58\%), HIE/birth asphyxia (18.30\%) and jaundice requiring phototherapy (15.99\%) in the descending order followed by miscellaneous causes and neonatal sepsis. In our study, we had neonatal jaundice as the third most common cause of admission and morbidity probably due to more number of pre-term admissions. According to the data from national neonatal, perinatal database (NNPD, 2002-2003) comprising of 18 tertiary care neonatal units across India found sepsis to be one of the commonest cause of morbidity. ${ }^{8}$ Sepsis/pneumonia/ meningitis also have contributed significant proportion $(11.70 \%)$ in the present study.

\section{CONCLUSION}

Our study identified pre-term babies (57.57\%), respiratory distress syndrome (19.58\%), HIE (18.30\%), neonatal jaundice (15.99\%) and sepsis (11.70\%) as major causes of neonatal morbidity out of 5755 NICU admissions. Most of these morbidities are preventable up to some extent if detected and intervened in time, so as to reduce the morbidity and mortality. For scientific application of preventive strategies and therapeutic interventions in neonatology, we should have country/region/community-based clinical data on neonatal morbidity and mortality. This can only be achieved by whole hearted involvement of the clinicians in clinical research as well as publications.

\section{REFERENCES}

1. Singh M. Care of the new born. $8^{\text {th }}$ ed. CBS Publishers and Distributers 2014:2-4,10,63.

2. National neonatal forum. Report of national perinatal database 2000 .

3. Guidelines for perinatal care. $2^{\text {nd }}$ ed. American academy of pediatrics and American college of obstetricians and gynaecologists, 1998.

4. Parthasarsthy A, Borker AS, Nair MKC, et al. Fundamentals of paediatrics. $2^{\text {nd }}$ ed. New born care, Chap 3, 2013:421, 31.

5. Bhutam VK. Differential diagnosis of neonatal respiratory distress. In: Spitzer AR, ed. Intensive care of the fetus and neonate. St. Louis: Mosby Year Book 1996:496-505.

6. Greenough A, Robertson MRL. Respiratory distress syndrome. Cochrane database syst Rev 2008;3: CD000456.

7. Singh M, Deorari AK. Pneumonia in newborn babies. Indian J Pediatric 1995;62(3):293-306.

8. National neonatology forum. Report of the national perinatal database 2002-2003. New Delhi 2004. 